\title{
VDR FOK-I POLYMORPHISM IN THE POPULATION OF KERALA, INDIA
}

\author{
Joe Joseph ${ }^{1}$, Adithi K. P2, Anu Yamuna Joseph ${ }^{3}$ \\ ${ }^{1}$ Associate Professor, Department of Medicine, Government Medical College, Ernakulam, Kerala. \\ ${ }^{2}$ Postgraduate Student, Department of Biotechnology, Mar Athanasius College, Kothamangalam, Kerala. \\ ${ }^{3}$ Assistant Professor, Department of Biotechnology, Mar Athanasius College, Kothamangalam, Kerala.
}

\section{ABSTRACT}

\section{BACKGROUND}

Vitamin D receptor (VDR), a member of the steroid hormone receptor family is involved in a variety of biological processes such as bone metabolism, modulation of immune response, regulation of cell proliferation and differentiation. Polymorphisms in VDR gene has been linked to a number of diseases like osteoarthritis, cancer, diabetes, etc. Since ethnic variations has been reported in the allele frequency of VDR polymorphisms, population specific data has to be generated before conducting a valid genetic association study. India.

The aim of this study was to identify the distribution of VDR Fok-I polymorphism in the healthy individuals of Kerala, South

\section{MATERIALS AND METHODS}

This study was conducted on 152 unrelated individuals of Kerala. Detection of VDR Fok-I polymorphism was done by PCR-RFLP. The allele and genotype frequencies were calculated from the genotype data. Genotype frequencies of different populations were compared with that of ours using Chi square test.

\section{RESULTS}

The genotype distribution of VDR Fok-I in this population followed Hardy-Weinberg equilibrium. Significant variations were observed on comparing our genotype distribution with that of data from previous studies in different populations confirming ethnic variation in genotype frequency. Variations between different population groups within India were also observed.

\section{CONCLUSION}

This study confirms ethnic variations in the VDR Fok-I genotype distribution indicating the need for generating population specific data for different ethnic groups. Establishing such specific databases is essential for valid genetic association studies.

\section{KEYWORDS}

VDR, Polymorphism, Kerala Population, PCR-RFLP.

HOW TO CITE THIS ARTICLE: Joseph J, Adithi KP, Joseph AY. VDR Fok-I polymorphism in the population of Kerala, India. J. Evolution Med. Dent. Sci. 2017;6(81):5678-5681, DOI: 10.14260/jemds/2017/1232

\section{BACKGROUND}

Vitamin D, also known as Calciferol, is a fat soluble vitamin. Calcitriol, the biologically-active form of vitamin $\mathrm{D}$, regulates the concentration of calcium and phosphate in the bloodstream. It also affects neuromuscular function and inflammation, cell proliferation, differentiation and apoptosis. ${ }^{1}$ Vitamin D receptor (VDR) is a member of the steroid hormone receptor family that binds the active form of Vitamin D (1,2,5-dihydroxyvitamin D3) and interacts with the target cell nuclei to produce variety of biological effects. The binding of vitamin D to VDR is essential for the maintenance of calcium and phosphorous levels in the blood and the maintenance of mineral density. VDR is also known to be involved in cell proliferation and differentiation. A role for vitamin $\mathrm{D}$ in a number of diseases like, diabetes, cancer, cardiovascular diseases, etc. has been reported. The biological activity of Vitamin D is exerted through VDRmediated control of target genes. ${ }^{2}$

'Financial or Other Competing Interest': None.

Submission 18-09-2017, Peer Review 28-09-2017,

Acceptance 03-10-2017, Published 09-10-2017.

Corresponding Author:

Dr. Joe Joseph,

Department of Medicine,

Government Medical College,

Ernakulam, Kerala, India.

E-mail: joemundackal@yahoo.co.in

DOI: $10.14260 /$ jemds $/ 2017 / 1232$
Vitamin D receptor (VDR) is expressed throughout the body on a wide variety tissues and cells such as heart, kidney, immune cells etc. Hence, it has been associated with several renal, cardiovascular and inflammatory diseases. Several DNA sequence variations known as polymorphisms have been reported in VDR gene. These polymorphisms can have biological effects. Polymorphisms in the VDR gene is known to be associated with a number of diseases like osteoarthritis, diabetes, cancer, rickets, immunological diseases, etc. The effect of VDR polymorphisms on disease susceptibility has been widely investigated. ${ }^{3}$

VDR protein is encoded by the VDR gene located on human chromosome 12 q12-q22 region. ${ }^{4}$ It consists of 11 exons that span approximately $75 \mathrm{~kb}$. The non-coding 5 ' end of the VDR gene includes exons 1A, 1B and 1C. Eight exons encode the structural portion of the VDR gene which is 427 amino acids long with a molecular weight of 48289 daltons. ${ }^{5}$

Most of the polymorphisms in the VDR gene has been found to be in the 5' promoter and 3' UTR regions. The three adjacent RFLPs BsmI, ApaI and TaqI at the 3' end and the thymine/cytosine polymorphism at the first potential start site of VDR gene are the most frequently studied. The polymorphisms in the 3' UTR region are most probably associated with mRNA stability ${ }^{6}$ while the Fok-I polymorphism has been shown to affect the activity of the protein. The short 424 aa VDR protein variant corresponding to the $\mathrm{C}$ allele $(\mathrm{F})$ was found to be 1.7 -fold more active than the long 427 aa variant corresponding to the T allele (f). ${ }^{7}$ 
Genetic and epidemiological studies in the VDR gene will provide insight into the association between disease and VDR alleles. Since ethnic variation in allele frequency is widely documented,3,8 population specific data of VDR polymorphism has to be generated before conducting a valid genetic association study. In this study, we determined the frequency of VDR Fok-I polymorphism in a sample of Indian population. The allele frequencies were compared with those of other populations. We also verified whether the allelic distribution followed Hardy-Weinberg equilibrium.

\section{MATERIALS AND METHODS}

\section{Sample Size and Data Collection}

This was an observational study approved by the Institutional Ethics Committee. sample size used for convenience. Written informed consent was obtained from all the participants. $3 \mathrm{~mL}$ blood sample from each participant was collected into EDTA coated tubes.

\section{Genotyping}

Genomic DNA was isolated from blood samples by salting out method. ${ }^{9}$

VDR Fok-I polymorphism was analysed by PCR-RFLP method. The primers used for the PCR reaction were forward - 5'AGCTGGCCCTGGCACTGACTCTGCTCT-3' and Reverse - 5'ATGGAAACACCTTGCTTCTTCTCCCTC-3'.10 PCR reaction was carried out in $20 \mu \mathrm{L}$ reaction volume, containing 50ng of template DNA, $1.5 \mathrm{mM} \mathrm{MgCl}, 0.2 \mathrm{mM}$ dNTPs (Fermentas, USA), 10 picomoles of each primer, $1 \mathrm{U}$ of Taq polymerase (Sigma-Aldrich, India) and $1 \mathrm{X}$ Taq buffer. The cycling conditions consisted of an initial denaturation of 2 minutes at $95^{\circ} \mathrm{C}$, followed by 35 cycles of $94^{\circ} \mathrm{C}$ for 30 seconds, annealing at $58^{\circ} \mathrm{C}$ for 30 seconds and extension at $72^{\circ} \mathrm{C}$ for 45 seconds. A final extension was given at $72^{\circ} \mathrm{C}$ for 10 minutes. The PCR products were confirmed by agarose gel electrophoresis.

For PCR-RFLP analysis, the PCR product was digested with Fok-I restriction enzyme. Restriction digestion was done at $37^{\circ} \mathrm{C}$ for 5 minutes using 5 units of Fok-I fast digest enzyme (Fermentas, USA). The digested products were checked by agarose gel electrophoresis. Three different patterns were obtained: the FF genotype without the Fok-I restriction site showed only a single uncut band of 265 bp size, ff genotype generated two bands of 196 and $69 \mathrm{bp}$ and heterozygous Ff showed three bands of size 265, 196 and $69 \mathrm{bp}$.

\section{Statistical Analysis}

The genotyping data was used to estimate the allele frequencies and genotype frequencies. To verify whether the VDR Fok-I genotype distribution was in Hardy-Weinberg Equilibrium, the data was analysed using the chi-square test and the Hardy-Weinberg equilibrium calculator. ${ }^{11}$ Genotype frequencies of different populations were compared with that of ours using chi square test. ${ }^{12}$

\section{RESULTS}

VDR Fok-I allele frequencies and genotype distributions in the Kerala population are shown in Table 1. Of the total 152 samples analysed, 84 were homozygous FF, 56 were heterozygous $\mathrm{Ff}$ and 12 were homozygous ff. The allele frequency of $\mathrm{F}$ was $73.86 \%$ and that of was $26.31 \%$. The data obtained was analysed to verify if it was in Hardy-Weinberg equilibrium. The observed genotype frequency was used to calculate the expected frequency. Chi-square analysis was done to compare the observed and expected frequencies. A chi-square value of 0.38 with a p-value of 0.8269 at 0.05 significance level was obtained. This confirmed that the difference in the observed and expected genotype values were due to chance alone and hence the VDR Fok-I genotype distribution in the Kerala population is in Hardy-Weinberg equilibrium.

The frequency distribution of VDR Fok-I genotype of our population was compared with those found in previous studies (Table 2). Considerable variations were observed in the genotype distribution between ours and other populations. A goodness of fit test revealed that significant variations exist in the VDR Fok-I genotype distribution of Japanese, French, Canadian, European and Chinese Han populations when compared with our population. As expected, the genotype distribution of South Indian population obtained from a previous study was not significantly different from that of ours, but there was significant difference in the VDR Fok-I genotypes between North Indian population and our population.

\begin{tabular}{|c|c|c|c|c|c|}
\hline & \multicolumn{3}{|c|}{ Genotypes n (\%) } & \multicolumn{2}{c|}{$\begin{array}{c}\text { Allele } \\
\text { Frequencies n (\%) }\end{array}$} \\
\hline N & FF & Ff & Ff & F & f \\
\hline \multirow{2}{*}{152} & 84 & 56 & 12 & 224 & 80 \\
& $(55.26)$ & $(36.84)$ & $(7.89)$ & $(73.86)$ & $(26.31)$ \\
\hline \multicolumn{3}{|c|}{ Table 1. Genotype Distribution and Allele Frequencies of } \\
VDR Fok-I Polymorphism in the Healthy Population of \\
Kerala, India
\end{tabular}

\begin{tabular}{|c|c|c|c|c|c|c|}
\hline $\begin{array}{c}\text { Country/ } \\
\text { Ethnicity }\end{array}$ & No. & \multicolumn{2}{|c|}{ Genotype (n) } & \multirow{2}{*}{ p-value } & \multirow{2}{*}{ Reference } \\
\cline { 3 - 5 } $\begin{array}{c}\text { Kerala, } \\
\text { India }\end{array}$ & 152 & 84 & 56 & 12 & ref* & $\begin{array}{c}\text { Present } \\
\text { Study }\end{array}$ \\
\hline $\begin{array}{c}\text { North } \\
\text { Indian }\end{array}$ & 346 & 152 & 170 & 24 & $0.0385(\mathrm{~S})^{\dagger}$ & 13 \\
\hline $\begin{array}{c}\text { South } \\
\text { Indian }\end{array}$ & 80 & 43 & 29 & 8 & $0.8624(\mathrm{NS})^{\ddagger}$ & 14 \\
\hline $\begin{array}{c}\text { North } \\
\text { Indian }\end{array}$ & 160 & 80 & 79 & 1 & $0.0014(\mathrm{~S})^{\dagger}$ & 15 \\
\hline Japanese & 249 & 92 & 127 & 30 & $0.0015(\mathrm{~S})^{\dagger}$ & 16 \\
\hline $\begin{array}{c}\text { Chinese } \\
\text { Han }\end{array}$ & 176 & 55 & 78 & 43 & $0.0000028(\mathrm{~S})$ & 17 \\
\hline European & 2154 & 804 & 1036 & 314 & $0.00004(\mathrm{~S})^{\dagger}$ & 18 \\
\hline $\begin{array}{c}\text { French } \\
\text { Canadian }\end{array}$ & 1381 & 517 & 647 & 217 & $0.00005(\mathrm{~S})^{\dagger}$ & 19 \\
\hline
\end{tabular}

Table 2. VDR Fok-I Genotype Distributions of Various Populations in Comparison with Kerala Population

* Reference population, † Significant; $\neq$ Not significant $(\mathrm{p}>0.05)$

\section{DISCUSSION}

Large numbers of biological process are modulated by the vitamin D endocrine system including bone metabolism, modulation of the immune response, and regulation of cell proliferation, calcium absorption from the gut, and differentiation. Any defect in the VDR gene could modulate the metabolism of calcium thereby increasing the risk of developing different diseases mainly osteoporosis and calcium stones. Variation in the vitamin D receptor sequence have been linked to several other diseases like diabetes, cancer, asthma, SLE, cardiovascular diseases, tuberculosis, etc. Genetic and epidemiological studies in VDR gene facilitate the study of association between disease conditions and molecular sequences. Since genotypic frequency of each 
population is different, population specific data of VDR polymorphism has to be generated before conducting a valid genetic association study.

Variations in the vitamin D receptor sequence have been linked to several diseases. The most frequently studied polymorphisms in VDR gene are BsmI, ApaI, and TaqI, at the 3 ' end of the VDR gene and thymine/cytosine polymorphism (Fok-I) located at the first potential start site. Polymorphisms in 3' UTR region are probably non-functional, and are in linkage disequilibrium (LD) with one or more truly functional polymorphisms elsewhere in the VDR gene. However, Fok-I polymorphism is not in LD with any of the other polymorphisms and hence is considered as an independent marker in itself especially in diseases related to calcium metabolism.

In this study, polymorphism present in the exon 2 of VDR gene was detected using the enzyme Fok-I by PCR-RFLP analysis. VDR Fok-I genotype frequency was obtained for the control population. In case-control studies, the control population must be in Hardy-Weinberg Equilibrium. Otherwise that will be a faulty base data. In this study, the genotype frequency analysis was done and it was found to be in Hardy-Weinberg Equilibrium confirming that this can be definitely used as a background data for large population studies in future.

The allele frequency differences between ethnic groups most likely results from evolutionary process and population genetic behaviour. The findings of this study confirm ethnic variations in the VDR Fok-I genotypes. These variations are relevant in that they form the basis for the correlation between genotype and incidence of different diseases in such groups. In a previous study, variation in VDR Fok-I genotype distribution between Indian and world population was reported. ${ }^{12}$ Our study reports variation between different population groups within India. The VDR Fok-I genotypes of the population of Kerala which is a South Indian state were similar to that of an earlier study conducted in South Indian population which included samples from Tamil Nadu, another South Indian state. ${ }^{13}$ But our results were significantly different from the results of two different studies conducted in North Indian population. ${ }^{14,15}$ India being a multi-ethnic population, these results suggest that separate genotype data should be generated for each (ethnic) group before establishing epidemiological databases for valid genetic association studies.

\section{CONCLUSION}

The functional effect of the VDR polymorphisms might be same since the physiological role of VDR remains unchanged in different ethnic populations. However, these polymorphisms may be helpful in predicting the incidence of disease/phenotype between such groups. Association studies can indicate which VDR genotype is most likely associated with the disease causing genes, and hence can serve as diagnostic markers.

\section{REFERENCES}

[1] Cranney A, Horsley T, O'Donnell S, et al. Effectiveness and safety of vitamin $\mathrm{D}$ in relation to bone health. Evidence Report/Technology Assessment 2007;158:1-235.
[2] Haussler MR, Whitfield GK, Haussler CA, et al. The nuclear vitamin D receptor: biological and molecular regulatory properties revealed. Journal of Bone and Mineral Research 1998;13(3):325-49.

[3] Uitterlinden AG, Fang Y, van Meurs JB, et al. Genetics and biology of vitamin $\mathrm{D}$ receptor polymorphisms. Gene 2004;338(2):143-56.

[4] Szpirer J, Szpirer C, Riviere M, et al. The Sp1 transcription factor gene (SP1) and the 1,25dihydroxyvitamin D 3 receptor gene (VDR) are colocalized on human chromosome arm $12 \mathrm{q}$ and rat chromosome 7. Genomics 1991;11(1):168-73.

[5] Miyamoto K, Kesterson RA, Yamamoto $\mathrm{H}$, et al. Structural organization of the human vitamin D receptor chromosomal gene and its promoter. Molecular Endocrinology 1997;11(8):1165-79.

[6] Schaaf MJ, Cidlowski JA. AUUUA motifs in the $3^{\prime}$ UTR of human glucocorticoid receptor $\alpha$ and $\beta$ mRNA destabilize mRNA and decrease receptor protein expression. Steroids 2002;67(7):627-36.

[7] Arai $H$, Miyamoto $K$, Taketani $Y$, et al. A vitamin D receptor gene polymorphism in the translation initiation codon: effect on protein activity and relation to bone mineral density in Japanese women. Journal of Bone and Mineral Research 1997;12(6):915-21.

[8] Zmuda JM, Cauley JA, Ferrell RE. Molecular epidemiology of vitamin D receptor gene variants. Epidemiologic Reviews 2000;22(2):203-17.

[9] Miller SA, Dykes DD, Polesky HF. A simple salting out procedure for extracting DNA from human nucleated cells. Nucleic Acids Research 1988;16(3):1215.

[10] Harris SS, Eccleshall TR, Gross C, et al. The vitamin D receptor start codon polymorphism (Fok-I) and bone mineral density in premenopausal American black and white women. Journal of Bone and Mineral Research 1997;12(7):1043-8.

[11] Rodriguez S, Gaunt TR, Day IN. Hardy-Weinberg equilibrium testing of biological ascertainment for Mendelian randomization studies. American Journal of Epidemiology 2009;169(4):505-14.

[12] Preacher KJ. Calculation for the chi-square test: an interactive calculation tool for chi-square tests of goodness of fit and independence, 2001. http://quantpsy.org /chisq/chisq.htm

[13] Selvaraj P, Chandra G, Kurian SM, et al. Association of vitamin D receptor gene variants of BsmI, Apal and Fok-I polymorphisms with susceptibility or resistance to pulmonary tuberculosis. Current Science 2003:84(12):1564-8.

[14] Manchanda PK, Konwar R, Nayak VL, et al. Association of genetic variants of the vitamin $D$ receptor (VDR) gene (Fok-I, Taq-I and Bsm-I) with susceptibility of benign prostatic hyperplasia in a North Indian population. Asian Pac J Cancer Prev 2010;11(4):10058.

[15] Bid HK, Konwar R, Aggarwal CG, et al. Vitamin D receptor (Fok-I, BsmI and TaqI) gene polymorphisms and type 2 diabetes mellitus: a North Indian study. Indian J Med Sci 2009;63(5):187-94.

[16] Minamitani K, Takahashi Y, Minagawa M, et al. Difference in height associated with a translation start site polymorphism in the vitamin $\mathrm{D}$ receptor gene. Pediatric Research 1998;44(5):628-32. 
[17] Huang X, Cao Z, Zhang Z, et al. No association between Vitamin D receptor gene polymorphisms and nasopharyngeal carcinoma in a Chinese Han population. Bioscience Trends 2011;5(3):99-103.

[18] Jenab M, McKay J, Bueno-de-Mesquita HB, et al. Vitamin D receptor and calcium sensing receptor polymorphisms and the risk of colorectal cancer in European populations. Cancer Epidemiology and Biomarkers Prevention 2009;18(9):2485-91.
[19] Sinotte M, Rousseau F, Ayotte P, et al. Vitamin D receptor polymorphisms (FokI, BsmI) and breast cancer risk: association replication in two casecontrol studies within French Canadian population. Endocrine-Related Cancer 2008;15(4):975-83. 